\title{
SIMULAÇÃO DO BALANÇO HÍDRICO PARA A CULTURA DO CAFEEIRO NAS REGIÕ̉ES DE LAVRAS E UBERLÂNDIA
}

\section{WATER BALANCE SIMULATION FOR COFFEE CROP IN TWO REGIONS OF THE MINAS GERAIS STATE, BRAZIL}

\author{
Jorge Luiz Moretti de SOUZA ${ }^{1}$ \\ José Antônio FRIZZONE ${ }^{2}$
}

\begin{abstract}
RESUMO
O objetivo do presente trabalho consistiu em simular e avaliar os valores da evapotranspiração da cultura $(E T C)$, irrigação (I), evapotranspiração real $(E R)$ e deficiência hídrica $(D E F)$ da cultura do cafeeiro, em um modelo de balanço hídrico climatológico decendial, submetida a variações dos parâmetros irrigacionistas ao longo dos quatro primeiros anos de seu desenvolvimento, nas regiões de Lavras e Uberlândia, Estado de Minas Gerais. Os resultados obtidos mostraram que: (a) Nos anos "implantação", 1-2 e 2-3, os valores da ETc foram 35\%,20\% e 10\% menores que os valores verificados para a cultura adulta, respectivamente; (b) Considerando somente a precipitação provável a $75 \%$ de probabilidade $\left(P_{75 \%}\right)$, apenas 0 ano de implantação não apresentou risco de ocorrer $D E F>200 \mathrm{~mm} \mathrm{ano}^{-1}$; (c) Devido à ocorrência de deficiência hídrica e a fase fenológica do cafeeiro, especial atenção deve ser dada às irrigações realizadas de março a maio em Lavras, e de maio a junho e setembro a outubro em Uberlândia; (d) Foram necessários entre 7 e 8 irrigações ano ${ }^{-1}$ para aplicar um lâmina de irrigação entre $220 \mathrm{~mm}^{2} \mathrm{ano}^{-1}$ a $382 \mathrm{~mm}^{2} \mathrm{no}^{-1}$.
\end{abstract}

Palavras-chave: Evapotranspiração; deficiência hídrica; manejo; parâmetros; modelo

\begin{abstract}
The objective of this work was to simulate and to evaluate the values of crop evapotranspiration $(E T C)$, irrigation $(I)$, real evapotranspiration $(R E)$ and water deficit $(W D)$ of the coffee crop, in a decade climatic water balance model applied for irrigation, when the coffee crop and irrigation parameters were submitted to variations. The analyses were accomplished along four years of the coffee crop development, in the Lavras and Uberlândia regions, Minas Gerais state, Brazil. The results obtained with the model showed that: (a) In the years "implantation", 1-2 and 2-3, the values of the ETC were $35 \%, 20 \%$ and $10 \%$ smaller than the values for adult plants, respectively; (b) Considering the probable precipitation at the 75 percent level $\left(P_{75 \%}\right)$, only the year of the implantation did not present risk with $W D>200 \mathrm{~mm}^{-1 e a r^{-1}}$; (c) Due the occurrence of water deficiency and the coffee fenological phase, special attention should be given to the irrigations applied from March to May in Lavras, and from May to June and September to October in Uberlândia; (d) To apply $220 \mathrm{~mm}_{\text {year }}^{-1}$ to $382 \mathrm{~mm}$ year ${ }^{-1}$ of irrigation it was necessary 7 to 8 irrigations year ${ }^{-1}$.
\end{abstract}

Key-words: Evapotranspiration; water deficiency; management; parameters; model

\footnotetext{
${ }^{1}$ Engenheiro Agrícola, Doutor em Agronomia, Professor do Departamento de Solos e Engenharia Agrícola, Setor de Ciências Agrárias, Universidade Federal do Paraná (DSEA/SCA/UFPR). Rua dos Funcionários, 1540. Cep 80035-050, Curitiba, PR, Brasil. e-mail: jmoretti@ufpr.br *Autor para correspondência;

${ }^{2}$ Eng. Agrônomo, Professor Dr. no Departamento de Engenharia Rural/ESALQ/USP
} 


\section{INTRODUÇÃO}

As regiões Sul de Minas/Oeste e Triângulo Mineiro/Alto Paranaíba, localizadas no Estado de Minas Gerais, são responsáveis pela produção de $29,25 \%$ do café beneficiado produzido no Brasil (ABIC, 2006). No zoneamento agroclimático realizado para a cultura do cafeeiro, é possível verificar que as duas regiões possuem condições térmicas e hídricas satisfatórias para a cultura do café arábica (ANTUNES, 1978; EVANGELISTA et al., 2002). Entretanto, regiões climaticamente aptas para o cultivo do cafeeiro vêm sofrendo, freqüentemente, o efeito de estiagens prolongadas nos períodos críticos de demanda de água, promovendo queda de produção em várias lavouras nas regiões do Estado (ASSAD et al., 2004; SANTINATO et al., 1996). Curiosamente, diagnósticos realizados na região indicam que os cafeicultores sentem falta de resultados de pesquisas técnico-econômicas a respeito da irrigação. A época e a freqüência de sua utilização ainda não estão bem estabelecidas e poucos agricultores fazem um manejo da água baseando-se em métodos técnicos (SANTOS et al., 1998). SOUZA e FRIZZONE (2003) comentam que a maioria dos trabalhos desenvolvidos até o momento avalia apenas as necessidades de irrigação do cafeeiro por intermédio do balanço hídrico climatológico tradicional de THORTHWAITE e MATHER (1955), para um período mensal, adotando grande capacidade de água disponível no solo $(C A D)$, sem considerar o ciclo produtivo da cultura ao longo de sua vida útil.

No entanto, o desenvolvimento e a utilização de modelos de simulação do balanço hídrico voltado às atividades agrícolas têm se intensificado nos últimos anos. Com o advento da informática, as dificuldades operacionais para a solução de equações complexas e para o tratamento, associação e utilização de grandes seqüências de dados, deixaram de ser obstáculos. A evolução das técnicas de programação e o surgimento de linguagens de programação mais acessíveis, associadas a grande capacidade de processamento dos computadores pessoais, estão permitindo a evolução da modelagem. GOMES (2005), por exemplo, cita e descreve uma relação de pelo menos vinte e quatro trabalhos que envolveram diretamente ou indiretamente a realização de balanços hídricos para auxiliar na composição de modelos computacionais voltados à agricultura irrigada.

SOUZA (2001) desenvolveu em linguagem Visual Basic (macros), um programa possuindo uma série de módulos destinados ao estudo do planejamento de projetos de irrigação de culturas agrícolas. Dentre eles, o módulo "Balanço hídrico climatológico decendial irrigacionista" desenvolvido, baseou-se na metodologia de THORNTHWAITE e MATHER (1955). Porém, contém uma série de adaptações e opções que tratam especialmente da prescrição e quantificação da irrigação complementar, visando atender às necessidades de água no solo para qualquer tipo de cultura (perene ou anual). Dados edafo-climáticos podem ser inseridos pelo usuário, permitindo grande flexibilidade nas condições de manejo da irrigação $(I)$, armazenamento de água no solo ( $A R M)$, simulação da evapotranspiração de referência (ETo ) e de todo o balanço hídrico.

A utilização de modelos de balanço hídrico aprimorados, que empreguem apenas a simulação da ETo e chuva provável, pode proporcionar níveis tecnicamente aceitáveis de erro de estimativa dos seus componentes ( $E T C, A R M, E R, D E F$ e EXC). Como a cultura do cafeeiro explora diferentes profundidades de solo, em função de seu estádio de desenvolvimento e características fisiológicas, a capacidade de água disponível no solo $(C A D)$ está sempre sujeita a uma variação contínua ao longo dos anos e das estações do ano (PEREIRA, 2005; PEREIRA et al., 1997). Desta forma, a realização de simulações pode gerar dados fundamentais ao estabelecimento de alternativas de planejamento mais eficientes para utilização das reservas de água do solo para a irrigação da cultura (FRIZZONE, 2005; SOUZA, 2001; SOUZA e FRIZZONE, 2003).

Considerando a variação de parâmetros irrigacionistas, tais como ETo, chuva provável, manejo da irrigação, coeficiente de cultivo $(K c)$, fração de água disponível $(p)$ e profundidade efetiva do sistema radicular, o objetivo do presente trabalho consistiu em simular e avaliar ao longo dos quatro primeiros anos de desenvolvimento da cultura do cafeeiro, a variação dos valores da evapotranspiração da cultura $(E T C)$, irrigação $(I)$, evapotranspiração real $(E R)$ e deficiência hídrica $(D E F)$, nas regiões de Lavras e Uberlândia, Estado de Minas Gerais, em um programa voltado ao cálculo do balanço hídrico climatológico decendial irrigacionista.

\section{MATERIAL E MÉTODOS}

O presente trabalho foi realizado a partir de uma série de simulações de balanços hídricos, realizadas com auxílio de um módulo do programa denominado "MORETTI - Modelo para a análise de risco econômico aplicado ao planejamento de projetos de irrigação para a cultura do cafeeiro", desenvolvido por SOUZA (2001).

As cidades de Lavras e Uberlândia, localizadas na região Sul de Minas e Triângulo Mineiro, respectivamente, foram escolhidas para compor os cenários de simulação do balanço hídrico para a cultura do cafeeiro. O clima predominante nas duas regiões, de acordo com os critérios propostos por Wilhen Köppen, classifica-se como Cwa e Cwb para a região Sul de Minas Gerais e Cwb e Aw para o Triângulo Mineiro. O Cwa ocorre nas regiões menos altas e o Cwb nas regiões mais altas, em que a temperatura média do mês mais frio é inferior a $18^{\circ} \mathrm{C}$ e superior $\mathrm{a}-3^{\circ} \mathrm{C}$, como é o caso de Lavras e Uberlândia (ANTUNES, 1986).

O módulo "Balanço hídrico climatológico decendial irrigacionista" do MORETTI, assim como 
qualquer outro programa que se destina a realização de balanços hídricos, necessita ser alimentado com uma série de dados e opções. Na Figura 1 encontrase um fluxograma simplificado contendo a estrutura lógica de algumas partes do módulo utilizado para realizar as análises.

Os parâmetros climáticos de entrada no modelo (Figuras 2 e 3 ) foram obtidos a partir das seguintes seqüências de dados climáticos diários de temperatura média do ar e chuva: (a) 17 anos de dados coletados na estação climatológica da região de Lavras, a $21^{\circ} 14^{\prime}$ de latitude sul, longitude $45^{\circ} 00^{\prime}$ W e 915 m de altitude média; (b) 8 anos de dados coletados na região de Uberlândia, a $18^{\circ} 55^{\prime}$ de latitude Sul, 48 $17^{\prime} \mathrm{W}$ e altitude média de $872 \mathrm{~m}$. Maiores detalhes sobre a metodologia para tratamento dos dados, cálculo da ETo decendial, cálculo da chuva provável, obtenção dos parâmetros estatísticos e processo de simulação, podem ser verificadas no trabalho de SOUZA (2001), e complementados em ASSIS et al. (1996), SOUZA e FRIZZONE (2003) e FRIZZONE et al. (2005).

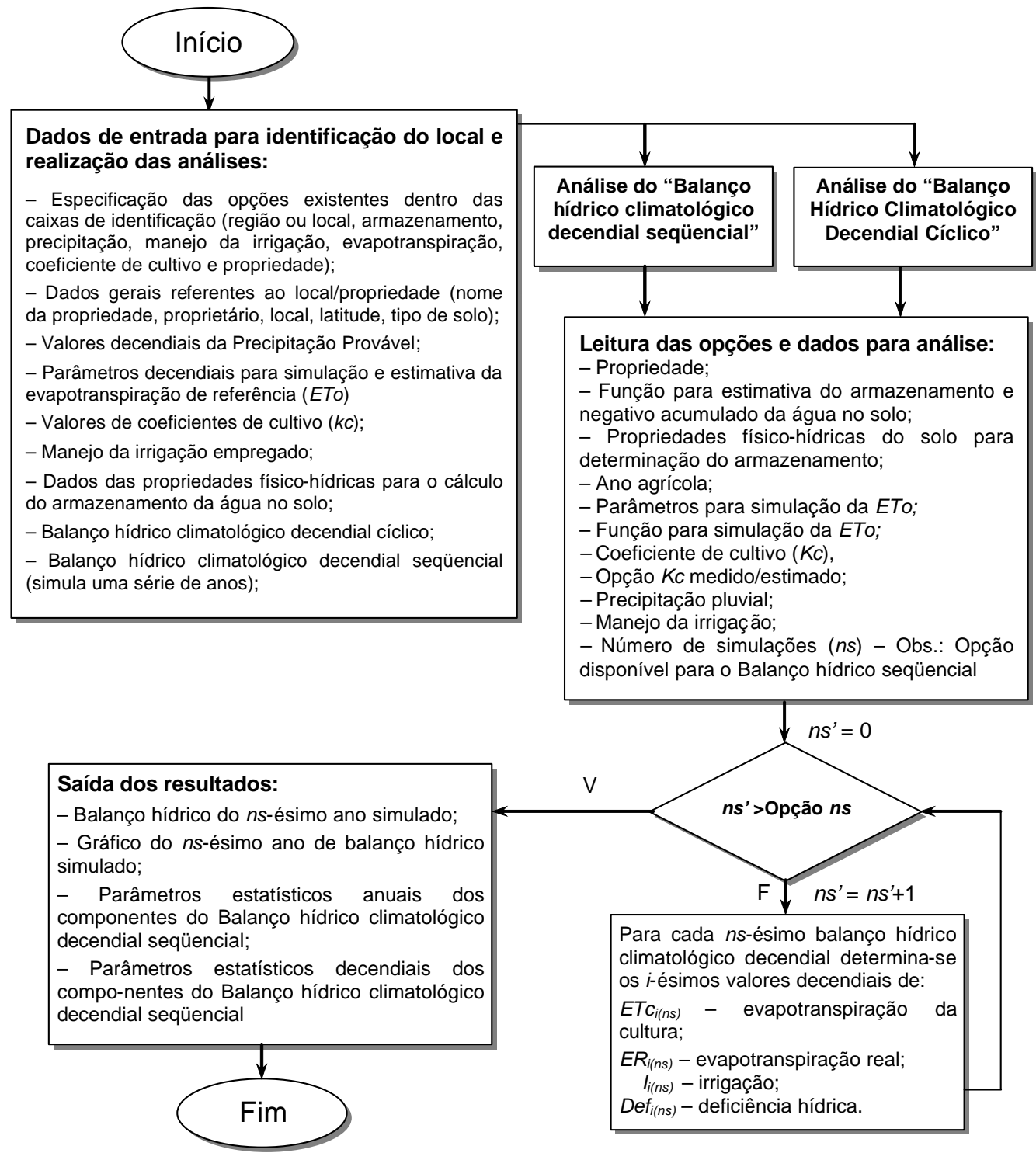

FIGURA 1 - Fluxograma contendo a estrutura lógica de algumas partes do módulo "Balanço hídrico climatológico decendial irrigacionista" do modelo MORETTI 


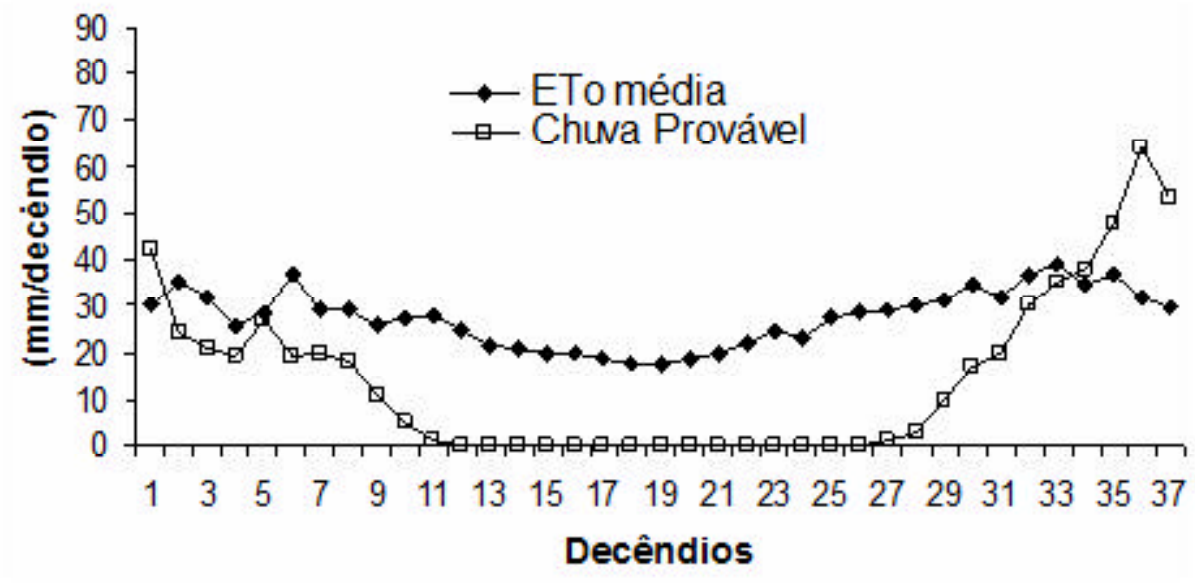

FIGURA 2 - Valores decendiais de ETo média e chuva provável (75\%) na região de Lavras.

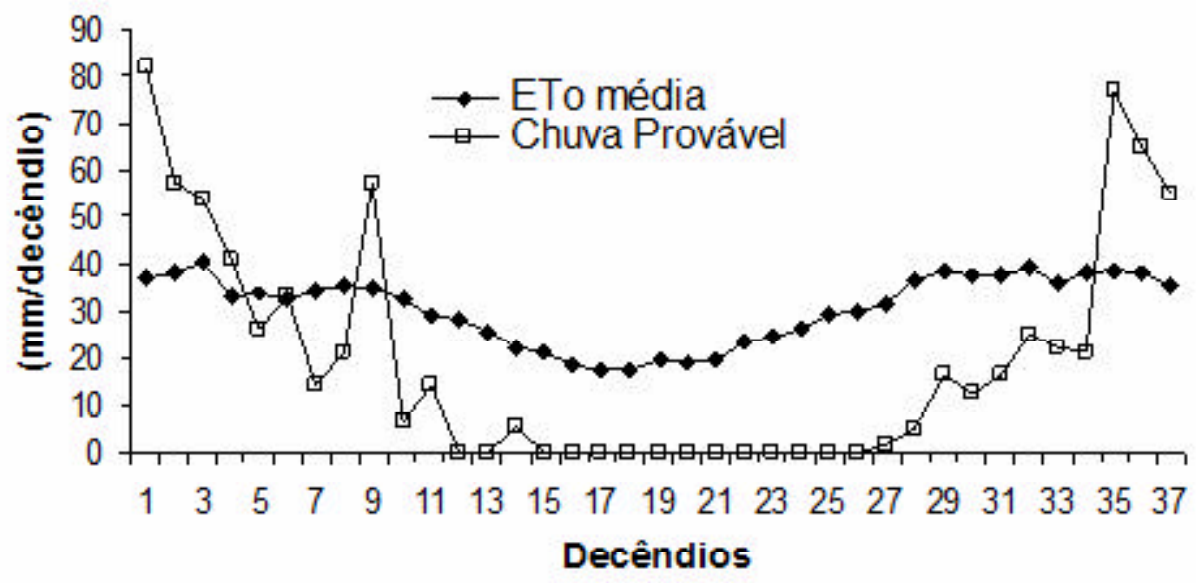

FIGURA 3 - Valores decendiais de ETo média e chuva provável (75\%) na região de Uberlândia.

Sendo assim, as análises de simulação foram realizadas a partir da seguinte série de dados de entrada e dos seguintes procedimentos de cálculo disponíveis nas rotinas do modelo balanço hídrico, para as cidades de Lavras e Uberlândia:

(a) Valores decendiais de chuva provável a $75 \%$ $\left(P_{75 \%}\right)$

Os valores decendiais de chuva utilizados como entrada no programa são prováveis a $75 \%$ $\left(P_{75 \%}\right)$ (Figuras 2 e 3). Esses valores foram estimados em planilha eletrônica Microsoft Excel 2000, considerando-se os parâmetros estatísticos da distribuição de probabilidade Gama, obtidos com o auxílio do módulo "Distribuição de freqüência e teste de aderência" do MORETTI (SOUZA, 2001). O módulo utiliza o teste de Kolmogorov-Smirnov a $5 \%$ de probabilidade para verificar a existência de ajustamento entre os dados medidos e estimados. Conforme as recomendações de ASSIS et al. (1996), adotou-se o conceito de distribuição mista, pois a função Gama não admite valores nulos.

(b) Parâmetros decendiais para simulação e estimativa da ETo decendial

Os valores decendiais de ETo utilizados na entrada do modelo (Figuras 2 e 3 ) foram obtidos a partir de uma série de medidas de um evapotranspirômetro tipo Thornthwaite-modificado na região de Lavras e estimados pelo método de THORNTHWAITE, para a região de Uberlândia, seguindo-se as recomendações de PEREIRA et al. (1997). Empregou-se a distribuição de probabilidade normal para simular os valores de ETo das duas regiões, nos decêndios de cada ano de balanço hídrico.

(c) Valores de coeficientes de cultivo $(K c)$

Para transformar a ETo em Evapotranspiração da Cultura (ETC) ao longo dos decêndios do ano, consideraram-se, como entrada no modelo, os valores de coeficiente de cultivo $(K c)$ da fase adulta da cultura (Tabela 1), estimado por CAMARGO e PEREIRA (1990). Os valores de Kc para os anos de implantação, 1-2 e 2-3 da cultura, foram determinados seguindo a proporção observada nos dados apresentados por SANTINATO et al. (1996). As proporções adotadas em relação aos valores da cultura adulta foram: $65 \%$ para o ano de implantação; $80 \%$ para o ano $1-2$; e $90 \%$ para o ano $2-3$. Não houve distinção entre os valores de $K c$ utilizados nas análises feitas para as duas regiões. 
TABELA 1 - Valor mensal do coeficiente de cultivo $(K c)$ na fase adulta da cultura.

\begin{tabular}{cccccccc}
\hline Mês & Valor $K c$ & Mês & Valor $K c$ & Mês & Valor $K c$ & Mês & Valor $K c$ \\
\hline Jan. & 0,89 & Abr. & 0,79 & Jul. & 0,73 & Out. & 0,89 \\
Fev. & 0,87 & Maio & 0,73 & Ago. & 0,73 & Nov. & 0,90 \\
Mar. & 0,91 & Jun. & 0,73 & Set. & 0,74 & Dez. & 0,95 \\
\hline
\end{tabular}

Fonte: CAMARGO e PEREIRA (1990)

\section{(d) Manejo da irrigação empregado}

O programa utilizado sempre considera que o manejo da irrigação empregado nas irrigações dos decêndios é complementar. Desta forma, a irrigação em um determinado decêndio ao longo do ano somente é realizada se duas condições forem satisfeitas: se a irrigação no decêndio foi habilitada (realizada em um formulário do programa); e se o armazenamento $(A R M)$ e a fração de água disponível no solo $(p)$ acusarem a necessidade de irrigação (verificada na simulação do balanço hídrico) (FRIZZONE et al. 2005, SOUZA, 2001). Baseando-se nos dados apresentados por SANTOS et al. (1998), seis manejos de irrigação complementar foram empregados nas análises de simulação ao longo de todo o ano (Tabela 2).

TABELA 2 - Manejos de irrigação complementar utilizados nas análises de simulação.

\begin{tabular}{c|c|c|c|c|c|c|c|c|c|c|c|c}
\hline \multirow{2}{*}{ Manejo } & \multicolumn{8}{c}{ Decêndios ao longo do ano } \\
\cline { 2 - 14 } & $1-3$ & $4-6$ & $7-9$ & $10-12$ & $13-15$ & $16-18$ & $19-21$ & $22-24$ & $25-27$ & $28-30$ & $31-33$ & $34-37$ \\
\hline Manejo 1 & & & & & & & & & & & & \\
\hline Manejo 2 & & & & & & & & & & & & \\
\hline Manejo 3 & & & & & & & & & & & & \\
\hline Manejo 4 & & & & & & & & & & & \\
\hline Manejo 5 & & & & & & & & & & & \\
\hline Manejo 6 & & & & & & & & & & & \\
\hline
\end{tabular}

(e) Atributos físico-hídricos para o cálculo do armazenamento da água no solo

O formulário de entrada dos parâmetros físico-hídricos do solo no programa balanço hídrico permite que os mesmos possam ser alterados. Assim, diferentes valores de capacidade de água disponível (CAD) podem ser obtidos (Equação 1). Nas análises de simulação realizadas, os valores de umidade de capacidade de campo $\left(U_{c C}\right)$, ponto de murcha permanente $\left(U_{P M P}\right)$ e densidade $(d)$ são de um Latossolo Vermelho-Amarelo (Tabela 3), e foram assumidos como invariáveis. A profundidade efetiva do sistema radicular $(z)$ do cafeeiro foi considerada igual nas duas regiões, sendo $20 \mathrm{~cm}$ para a cultura no ano de implantação, $30 \mathrm{~cm}$ no ano $1-2,40 \mathrm{~cm}$ no ano $2-3$ e $50 \mathrm{~cm}$ ano $X n$ (cultura adulta, ano 3-4 a $X_{n-1}-X_{n}$ ). 
SOUZA, J.L.M. e FRIZZONE, J.A. Simulação do balanço hídrico...

TABELA 3 - Atributos físico-hídricos do Latossolo Vermelho-Amarelo.

\begin{tabular}{lrc}
\hline \multicolumn{1}{c}{ Atributos físico-hídricos } & \multicolumn{2}{c}{ Profundidade efetiva do sistema radicular } \\
& $<25 \mathrm{~cm}$ & $25 \mathrm{~cm} \mathrm{a} 50 \mathrm{~cm}$ \\
\hline Capacidade de campo (\%) * & 34,76 & 33,33 \\
Ponto de murcha (\%) * & 17,86 & 17,98 \\
Densidade do solo $\left(\mathrm{g} \mathrm{cm}^{-3}\right)$ & 1,18 & 1,10 \\
\hline
\end{tabular}

* A umidade do solo na capacidade de campo e ponto de murcha são com base em peso

Os valores da capacidade de água disponível no solo $(C A D)$ e água disponível do solo $(A D)$ são calculados no programa a partir das Equações 1 e 2.

$$
\begin{aligned}
& C A D=\frac{\left(U_{C C}-U_{P A P}\right) \cdot d \cdot z}{100 \cdot d_{a}} \\
& A D=C A D \cdot p
\end{aligned}
$$

sendo, $C A D$ capacidade de água disponível $(\mathrm{mm}) ; U_{C C}$ a umidade do solo na capacidade de campo, com base em peso (\%); $U_{P M P}$ a umidade do solo no ponto de murcha permanente, com base em peso (\%); $d$ a densidade do solo $\left(\mathrm{g} \mathrm{cm}^{-3}\right) ; d$ densidade da água $\left(\mathrm{g} \mathrm{cm}^{-3}\right)$ - considerada igual a 1 $\mathrm{g} \mathrm{cm}^{-3} ; z$ a profundidade do volume de controle ou profundidade efetiva do solo $(\mathrm{mm}) ; A D$ água disponível no solo $(\mathrm{mm}) ; p$ fração de água disponível no solo para uma determinada cultura (adimensional).

A Tabela 4 apresenta os valores da fração $p$ adotados nas análises para determinar a água disponível no solo em cada $i$-ésimo decêndio, de acordo com as recomendações de FARIA e RESENDE (1997).

TABELA 4 - Fração de água disponível no solo para o cafeeiro.

\begin{tabular}{cccccc}
\hline Mês & Fração $p$ & Mês & Fração $p$ & Mês & Fração $p$ \\
\hline Jan. & 0,6 & Maio & 0,5 & Set. & 0,4 \\
Fev. & 0,6 & Jun. & 0,5 & Out. & 0,4 \\
Mar. & 0,6 & Jul. & 0,9 & Nov. & 0,5 \\
Abr. & 0,6 & Ago. & 0,6 & Dez. & 0,6 \\
\hline
\end{tabular}

A estimativa do armazenamento de água no solo e, ou, "negativo acumulado" para a simulação dos balanços hídricos ao longo do ano foi realizada com a Função Potencial de primeira ordem (Equação 4). Essa equação é originada de uma adaptação da equação de THORNTHWAITE e MATHER (1955) ao conceito de fração $p$ e água disponível $(A D)$ de RIJTEMA e ABOUKHALED (SOUZA, 2001; SOUZA e FRIZZONE, 2003). As condições para sua aplicação são:

- Quando $C A D_{i}\left(1-p_{d}\right)<A R M_{d}$ d" $C A D_{i}$, adota-se a equação,

$$
A R M_{d}=C A D_{i}-L_{d}
$$

- Quando $0<A R M_{d}$ d" $C A D_{i}\left(1-p_{d}\right)$, adota-se a equação,

$$
A R M_{d}=C A D_{i} \cdot\left(1-p_{d}\right) \cdot e^{\frac{C A D_{d} \cdot y_{d}-L_{d}}{C A D_{i} \cdot\left(1-y_{d}\right)}}
$$

sendo, $A R M_{d}$ armazenamento de água do solo no $d$-ésimo decêndio $(\mathrm{mm}) ; C A D$ capacidade de água disponível no $i$-ésimo ano $(\mathrm{mm}) ; L_{d}$ negativo acumulado no $d$-ésimo decêndio $(\mathrm{mm}) ; p_{d}$ fração de água disponível no solo para a cultura no $d$-ésimo decêndio (adimensional). 


\section{(f) Outras opções}

As simulações foram realizadas com a opção "Balanço hídrico climatológico decendial irrigacionista seqüencial", que simula uma série de anos sequencialmente.

O módulo "Balanço hídrico climatológico decendial irrigacionista" do MORETTI possibilita optar pelo número de simulações nas análises. Desta forma, como o número ótimo ou adequado de simulações permite maior confiabilidade nos resultados obtidos nas análises, um cenário visando esta verificação foi composto antes de proceder às análises de balanço hídrico nas duas regiões. As opções utilizadas foram: (a) ETC simulada a partir da ETo da região de Lavras; (b) cultura adulta (Ano $X n)$; (c) distribuição normal para simular a ETo; (d) 38 análises de simulação variando de 2 até 10.000 simulações, totalizando 109.452 simulações.

\section{RESULTADOS E DISCUSSÃO}

Os valores decendiais de $P_{75 \%}$ e ETo média, estimados para servir de entrada no programa e compor os cenários de balanço hídrico nas regiões de Lavras e Uberlândia (Figuras 2 e 3), permitem observar que: (a) Em média a região de Lavras apresenta ETo de $1.001,9 \mathrm{~mm} a^{-1}$ e a região de Uberlândia $1.114,8 \mathrm{~mm} \mathrm{ano}^{-1}$. Para cada trimestre do ano, em média, os decêndios da região de Uberlândia apresentaram valores de ETo 5,2, 1,7, 1,4 e 4,0 mm decêndio ${ }^{-1}$ maiores do que na região de Lavras; (b) A região de Lavras apresenta precipitação média de $1.441 \mathrm{~mm}$ ano-1 e a região de Uberlândia de $1.588 \mathrm{~mm}$ ano $^{-1}$. As duas regiões possuem as estações chuvosa (outubro a fevereiro) e seca (março a setembro) bem definidas; (c) As duas localidades apresentaram, predominantemente, valores de ETo média maiores que a $P_{75 \%}$, sendo o valor acumulado dessa diferença igual a $-491 \mathrm{~mm}$ ano ${ }^{-1}$ para Lavras e $-401 \mathrm{~mm} \mathrm{ano}^{-1}$ para Uberlândia. As regiões de Lavras e Uberlândia apresentaram 5 e 9 decêndios, respectivamente, com $P_{75 \%}$ maior que a ETo média. O saldo positivo ocorre, predominantemente, do final da primavera até o término do verão; (d) O maior valor de ETo decendial para Lavras foi de $39,0 \mathrm{~mm}$ decêndio ${ }^{-1}$ e ocorreu no decêndio 33 (17/11 a 26/11) e o menor valor foi de $17,3 \mathrm{~mm}$ decêndio ${ }^{-1}$ e ocorreu no decêndio 18 (20/06 a 29/06). O maior valor de ETo decendial para Uberlândia foi de $40,2 \mathrm{~mm}$ decêndio ${ }^{-1}$ e ocorreu no decêndio $3(21 / 01$ a 30/01) e o menor valor foi de $17,2 \mathrm{~mm}$ decêndio ${ }^{-1}$ e ocorreu no decêndio 18 (20/06 a 29/06); (e) Os valores médios de ETo e $P_{75 \%}$ obtidos nas duas regiões estão dentro dos limites encontrados por outros autores (CASTRO NETO e SILVEIRA, 1983; JORDÃO et al., 1996; SANTOS e RIBEIRO, 2004) para diversas regiões do Estado de Minas Gerais. No entanto, apesar dos valores decendiais de $P_{75 \%}$ de Uberlândia ajustarem-se à distribuição de probabilidade Gama, a $5 \%$ de probabilidade, acredita-se mediante as considerações de alguns autores (CASTRO NETO e SILVEIRA, 1983; ASSIS, 1996; FRIZZONE et al., 2005) que os resultados foram estimados a partir de uma série pouco representativa de dados pluviométricos, com apenas 8 anos.

As seguintes características podem ser verificadas nos parâmetros estatísticos (menor e maior valor, moda e média) da $E T c(\mathrm{~mm}$ ano-1) obtidos a partir das 38 análises de simulação (109.452 simulações) realizadas para a distribuição de probabilidade normal, na região de Lavras (Figura 4): (a) Não foram verificadas diferenças maiores que $5 \%$ para os parâmetros estatísticos a partir de 1.500 simulações. Os desvios padrão das diferenças, obtidos das 18 análises realizadas entre $1.500 \mathrm{a}$ 10.000 simulações ficaram em $1,06 \%, 0,56 \%, 1,06 \%$, $0,37 \%$, respectivamente, para o menor e maior valor, moda e média; (b) Em relação ao valor obtido com 10.000 simulações, a média não apresentou diferenças maiores que $1 \%$ acima de 80 simulações; (c) O desempenho do modelo nas simulações da ETC na região de Uberlândia, em um cenário idêntico, foi muito parecido com os resultados obtidos para a região de Lavras, sendo que apenas a grandeza dos valores foi diferente.

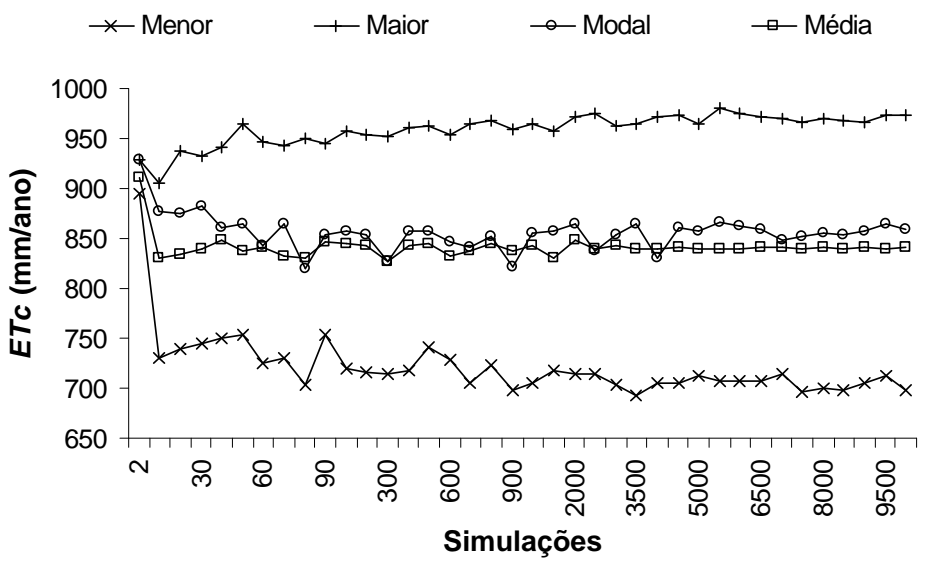

FIGURA 4 - Parâmetros estatísticos da ETC do cafeeiro adulto, simulados com a distribuição de probabilidade normal, para a região de Lavras-MG. 
Os valores de ETC simulados no programa MORETTI ao longo dos anos de desenvolvimento da cultura do cafeeiro (Tabela 5), em mm ano-1, resultaram do somatório das simulações da ETC em $\mathrm{mm}$ decêndio ${ }^{-1}$, e evidenciam que: (a) Os extremos da $E T C$ simulada para a região de Lavras, mostram que dificilmente os valores alcançados poderão ser inferiores a $455,6 \mathrm{~mm}$ ano ${ }^{-1}$ no período de implantação e superiores a $967,9 \mathrm{~mm}$ ano ${ }^{-1}$ na fase adulta da cultura. Os extremos da ETc na região de Uberlândia mostrou menor amplitude, porém, foram maiores, sendo $560,4 \mathrm{~mm}$ ano ${ }^{-1}$ (implantação) e 1008,0 mm ano-1 (ano Xn); (b) Em média, os valores $E T c$ da cultura adulta ficaram em $839,8 \mathrm{~mm}$ $\operatorname{ano}^{-1}\left(\mathrm{~s}=46,4 \mathrm{~mm}\right.$ ano $\left.{ }^{-1}\right)$ para a região de Lavras, e $937,7 \mathrm{~mm} a^{-1}\left(s=26,2 \mathrm{~mm}^{-1} \mathrm{ano}^{-1}\right)$ para a região de Uberlândia. (c) A cultura do cafeeiro evapotranspirou nos anos de implantação, 1-2 e 2-3, em torno de $35 \%, 20 \%$ e $10 \%$ a menos, respectivamente, que a cultura adulta (ano $X n$ ). Os resultados obtidos das simulações (Tabela 5) são interessantes, pois mostram um desdobramento das proporções sugeridas na literatura (CAMARGO e PEREIRA, 1990; SANTINATO et al., 1996) para os valores de $K c$ do cafeeiro adulto, para os anos de implantação, 1-2 e 2-3 da cultura, dentro de um balanço hídrico seqüencial. Desta forma, parâmetros estatísticos dos valores de ETC (menor, maior, modal e média) para os anos de desenvolvimento do cafeeiro puderam ser quantificados, disponibilizando dados alternativos para planejar e decidir aspectos relacionados aos projetos com a cafeicultura irrigada nas região de Lavras e Uberlândia.

TABELA 5 - Parâmetros estatísticos da $E T c\left(\mathrm{~mm}^{2} \mathrm{ano}^{-1}\right)$, simulada para os anos de desenvolvimento do cafeeiro na região de Lavras e Uberlândia.

\begin{tabular}{lcccccccccc}
\hline \multirow{2}{*}{ Anos } & \multicolumn{4}{c}{ Região de Lavras } & \multicolumn{4}{c}{ Região de Uberlândia } \\
\cline { 2 - 11 } & Menor & Maior & Modal & Média & $s^{*}$ & Menor & Maior & Modal & Média & $s^{*}$ \\
\hline Implantação & 455,6 & 629,9 & 559,6 & 546,0 & 30,6 & 560,4 & 655,6 & 613,1 & 609,5 & 17,2 \\
Ano 1-2 & 563,2 & 776,6 & 689,6 & 672,0 & 37,5 & 689,4 & 805,7 & 757,8 & 750,2 & 21,4 \\
Ano 2-3 & 629,6 & 875,2 & 775,0 & 755,9 & 42,5 & 774,3 & 907,2 & 847,8 & 844,1 & 23,5 \\
Ano Xn & 701,6 & 967,9 & 859,4 & 839,8 & 46,4 & 859,5 & 1008,0 & 945,6 & 937,7 & 26,2 \\
\hline
\end{tabular}

*Desvio padrão da média da $E T c\left(\mathrm{~mm}^{2}\right.$ ano $\left.^{-1}\right)$ estimada em 10.000 simulações

Os atributos físico-hídricos do Latossolo utilizado (Tabela 3) permitiram a obtenção das seguintes capacidades de água disponível no solo $(C A D)$ para a cultura do cafeeiro: $39,9 \mathrm{~mm}$ na implantação, $58,3 \mathrm{~mm}$ no ano $1-2,75,2 \mathrm{~mm}$ no ano 2-3 e 92,1 $\mathrm{mm}$ no ano $X n$. Baseando-se nesses quatro anos, a Tabela 6 apresenta os valores médios da lâmina de irrigação $(I)$, evapotranspiração real $(E R)$ e deficiência $(D E F)$.

Em relação ao manejo que realiza irrigações complementares durante todo o ano (manejo 1), verificou-se para a região de Lavras, nos anos de desenvolvimento da cultura (implantação, 1-2, 2-3 e $X n)$, que a diferença percentual média nas lâminas de irrigação aplicadas nos manejos 2, 3, 4 e 5 ficaram, respectivamente, 9,8\%, 11,3\%, 19,9\% e $41,2 \%$ menores. A proximidade entre os valores de irrigações obtidos com os manejos 2 e 3 mostra que os meses de janeiro e fevereiro (decêndios 1 a 6) e novembro e dezembro (decêndios 32 a 37), em média, interferem muito pouco na lâmina anual de irrigação que se aplica na cultura do cafeeiro nessa região. Por outro lado, a suspensão da irrigação nos meses de março, abril e maio nas análises de simulação proporcionaram diminuição percentual significativa nas irrigações realizadas com os manejos 4 e 5 , principalmente no mês de maio. Este fato indica que não é prudente realizar os manejos de irrigação 4 e 5 , pois de acordo com as fases fenológicas do cafeeiro arábica (CAMARGO e
CAMARGO, 2001; PEZZOPANE et al., 2003): no mês de março ainda está ocorrendo a fase da granação; e entre abril e maio está ocorrendo a fase de maturação dos frutos e indução e maturação das gemas florais nos galhos que irão frutificar no ano seguinte.

Para a região de Uberlândia, verificou-se nos anos de desenvolvimento da cultura (implantação, 1-2, 2-3 e Xn), em relação ao manejo que realiza irrigações complementares durante todo o ano (manejo 1), que a diferença percentual média nas lâminas de irrigação realizadas nos manejos 2, 3, 4 e 5 ficaram, respectivamente, $14,4 \%, 17,6 \%$, $17,6 \%$ e $32,6 \%$ menores. A proximidade entre os valores médios de irrigação realizados nos manejos 2 , 3 e 4 mostra que as deficiências encontram-se concentradas entre o início de maio e meados de outubro (decêndios 13 a 30 ). A suspensão da irrigação entre os meses de novembro e dezembro (decêndios 33 a 37) e de janeiro e abril (decêndios 1 a 12), em média, interferiram pouco na lâmina anual de irrigação que se aplica na cultura do cafeeiro nessa região. Desta forma, especial atenção deve ser dada às irrigações a serem realizadas nos meses de maio e junho, por ser a fase de maturação dos frutos e gemação floral nos galhos que vão frutificar no ano seguinte e, setembro e outubro, devido à fase de floração e frutificação (CAMARGO e CAMARGO, 2001; PEZZOPANE et al., 2003). 
TABELA 6 - Valores médios de irrigação (I), evapotranspiração real (ER) e deficiência (DEF), obtidos nas simulações do balanço hídrico ao longo dos anos de desenvolvimento do cafeeiro, para as regiões de Lavras e Uberlândia-MG.

\begin{tabular}{|c|c|c|c|c|c|c|c|c|c|c|c|c|}
\hline \multirow{2}{*}{ Anos } & \multicolumn{6}{|c|}{ Região de Lavras } & \multicolumn{6}{|c|}{ Região de Uberlândia } \\
\hline & 1 & 2 & 3 & 4 & 5 & 6 & 1 & 2 & 3 & 4 & 5 & 6 \\
\hline \multicolumn{13}{|c|}{ Valores médios de irrigação (mm/ano) para o cafeeiro } \\
\hline Implantação & 192,8 & 164,6 & 165,5 & 156,4 & 114,4 & - & 172,8 & 137,1 & 147,0 & 147,3 & 120,5 & - \\
\hline Ano 1-2 & 263,5 & 235,0 & 235,0 & 211,4 & 156,7 & - & 258,0 & 218,1 & 201,6 & 201,7 & 166,0 & - \\
\hline Ano 2-3 & 321,8 & 297,2 & 288,9 & 256,2 & 188,8 & - & 305,1 & 269,7 & 242,6 & 242,6 & 199,2 & - \\
\hline Ano $X n$ & 382,4 & 359,6 & 344,9 & 304,1 & 220,1 & - & 328,0 & 295,2 & 284,6 & 284,7 & 229,8 & - \\
\hline \multicolumn{13}{|c|}{ Valores médios de $E R$ (mm/ano) para o cafeeiro } \\
\hline Implantação & 531,0 & 502,7 & 502,7 & 496,0 & 451,1 & 361,5 & 585,9 & 550,6 & 551,9 & 552,2 & 525,4 & 427,2 \\
\hline Ano 1-2 & 660,2 & 630,6 & 630,7 & 607,7 & 553,6 & 427,2 & 731,4 & 693,4 & 689,6 & 689,4 & 654,1 & 505,2 \\
\hline Ano 2-3 & 745,2 & 719,1 & 719,1 & 686,9 & 621,5 & 467,6 & 833,5 & 796,6 & 786,6 & 786,4 & 745,0 & 560,6 \\
\hline Ano $X n$ & 831,6 & 805,0 & 805,0 & 763,2 & 684,4 & 494,7 & 930,3 & 893,3 & 877,0 & 877,2 & 826,1 & 611,6 \\
\hline \multicolumn{13}{|c|}{ Valores médios de deficiência (mm/ano) para o cafeeiro } \\
\hline Implantação & 15,0 & 43,3 & 43,3 & 50,1 & 95,0 & 184,7 & 24,1 & 58,6 & 57,6 & 57,8 & 83,7 & 182,5 \\
\hline Ano 1-2 & 12,0 & 41,3 & 41,5 & 64,3 & 118,3 & 244,8 & 19,0 & 56,8 & 60,7 & 60,7 & 96,3 & 244,5 \\
\hline Ano 2-3 & 9,4 & 36,5 & 36,9 & 69,2 & 134,5 & 288,7 & 11,1 & 47,4 & 57,7 & 57,4 & 99,9 & 284,1 \\
\hline Ano $X n$ & 8,2 & 33,4 & 34,8 & 77,1 & 155,1 & 345,2 & 7,8 & 44,3 & 60,7 & 60,8 & 111,7 & 326,1 \\
\hline
\end{tabular}

Os dados apresentados na Tabela 7 são os resultados obtidos da relação entre os valores médios de ETc e ER, entre os anos de desenvolvimento da cultura do cafeeiro, nas regiões de Lavras e Uberlândia, ocorridas em função do tipo de manejo de irrigação (1 a 6) adotado, considerando a ocorrência de uma $P_{75 \%}$. De forma geral, as menores diferenças ficaram entre $0,8 \%$ e $3,9 \%$ para o manejo 1 de irrigação, o que era esperado, pois estava sendo realizado irrigação complementar ao longo de todo o ano. As maiores diferenças ficaram entre $29,9 \%$ e $41,1 \%$ para o manejo que desconsidera o uso da irrigação (manejo 6), prevendo apenas chuva provável a 75\% $\left(P_{75 \%}\right)$.

Nos anos de desenvolvimento da cultura, o manejo de irrigação complementar durante todo o ano (manejo 1) proporcionou deficiência hídrica média de apenas $11,1 \mathrm{~mm}^{2} \mathrm{ano}^{-1}$ para Lavras, e 15,5 $\mathrm{mm}$ ano $^{-1}$ para Uberlândia (Tabela 6). É importante enfatizar que parte das deficiências hídricas obtidas com o uso da função Potencial de primeira ordem e manejo 1 , deve-se ao fato do balanço hídrico ser decendial e permitir a realização de apenas uma irrigação complementar em cada decêndio.

TABELA 7 - Diferença percentual relativa entre os valores médios de ETC e ER, verificada nos anos de desenvolvimento da cultura do cafeeiro nas regiões de Lavras e Uberlândia, em função do tipo de manejo de irrigação (1 a 6) adotado.

\begin{tabular}{lccccccccccccc}
\hline \multirow{2}{*}{ Anos } & \multicolumn{1}{c}{ Região de Lavras } & \multicolumn{1}{c}{ Região de Uberlândia } \\
\cline { 2 - 14 } & 1 & 2 & 3 & 4 & 5 & 6 & 1 & 2 & 3 & 4 & 5 & 6 \\
\hline Implantação & 2,7 & 7,9 & 7,9 & 9,2 & 17,4 & 33,8 & 3,9 & 9,7 & 9,5 & 9,4 & 13,8 & 29,9 \\
Ano 1-2 & 1,8 & 6,2 & 6,1 & 9,6 & 17,6 & 36,4 & 2,5 & 7,6 & 8,1 & 8,1 & 12,8 & 32,7 \\
Ano 2-3 & 1,4 & 4,9 & 4,9 & 9,1 & 17,8 & 38,1 & 1,3 & 5,6 & 6,8 & 6,8 & 11,7 & 33,6 \\
Ano Xn & 1,0 & 4,1 & 4,1 & 9,1 & 18,5 & 41,1 & 0,8 & 4,7 & 6,5 & 6,5 & 11,9 & 34,8 \\
\hline
\end{tabular}


Os dados da Tabela 6 e as informações disponíveis na bibliografia (ANTUNES, 1978; JORDÃO et al., 1996, SANTINATO et al., 1996) quanto à deficiência hídrica tolerada pela cultura do cafeeiro, permitem verificar também que: (a) No manejo que desconsidera o uso da irrigação (manejo 6), apenas o ano de implantação não apresenta risco de ocorrer deficiência anual maior do que $200 \mathrm{~mm}$. Devido à $P_{75 \%}$ utilizada nas análises, este fato evidencia, em média, que um em cada quatro anos pode apresentar condições inaptas à cafeicultura desenvolvida nas duas regiões; (b) Todos os manejos de irrigação testados (manejos 1 a 5) proporcionaram valores de deficiência próximo ou abaixo do limite de $150 \mathrm{~mm}$, o que segundo a bibliografia (ANTUNES, 1978; JORDÃO et al., 1996; SANTINATO et al., 1996) possibilita condições adequadas ao crescimento e produtividade do cafeeiro.Os valores de deficiência hídrica apresentados para as duas regiões (Tabela 6) referem-se a um turno de rega de 10 dias, pois o balanço hídrico é decendial. Assim, para um solo possuindo valores de $C A D$ semelhante aos utilizados nas análises, a aquisição de um sistema de irrigação projetado para trabalhar com um turno de rega entre 5 e 8 dias poderia suprir adequadamente as deficiências hídricas apresentadas pelo cafeeiro ao longo de sua vida útil. Um sistema com turno de rega entre 5 e 8 dias, diminuiria também parte das deficiências hídricas apresentadas, já que seria possível realizar mais de uma irrigação em um mesmo decêndio. Situações envolvendo manejos com mais de uma irrigação no decêndio não foram realizadas porque o módulo "Balanço hídrico climatológico decendial irrigacionista" do MORETTI não contempla este tipo de análise.

A Tabela 8 traz o número médio, mínimo e máximo de irrigações, por ano, nas 10.000 simulações. De forma geral, considerando a realização da irrigação para cultura do cafeeiro para períodos de dez dias (decêndios) e $P_{75 \%}$, verifica-se para Lavras e Uberlândia que: (a) $\mathrm{A}$ adoção do manejo 5 de irrigação $(C A D=39,9 \mathrm{~mm})$ demanda um mínimo de três irrigações por ano; (b) O manejo que realiza irrigações complementares o ano todo (manejo 1), demanda um máximo de doze irrigações por ano para Lavras nos anos de implantação e Ano 1-2 (CAD =58,3 mm) e treze irrigações por ano para Uberlândia, no ano de implantação; (c) Em média, para a fase adulta de desenvolvimento do cafeeiro (ano $X n, C A D=92,1$ $\mathrm{mm}$, manejo 1), espera-se a realização de oito e sete irrigações por ano, nas regiões de Lavras e Uberlândia, respectivamente.

TABELA 8 - Número médio, mínimo e máximo de irrigações, por ano, em 10.000 simulações, obtidas nos anos de desenvolvimento do cafeeiro, para as regiões de Lavras e Uberlândia

\begin{tabular}{|c|c|c|c|c|c|c|c|c|c|c|c|c|}
\hline \multirow{2}{*}{ Anos } & \multicolumn{6}{|c|}{ Região de Lavras } & \multicolumn{6}{|c|}{ Região de Uberlândia } \\
\hline & 1 & 2 & 3 & 4 & 5 & 6 & 1 & 2 & 3 & 4 & 5 & 6 \\
\hline \multicolumn{13}{|c|}{ Número médio de irrigações realizadas por ano para o cafeeiro (média de 10.000 anos simulados) } \\
\hline Implantação & 9 & 7 & 7 & 6 & 5 & - & 9 & 8 & 7 & 7 & 6 & - \\
\hline Ano 1-2 & 8 & 7 & 7 & 6 & 4 & - & 9 & 7 & 6 & 6 & 5 & - \\
\hline Ano 2-3 & 8 & 7 & 6 & 5 & 4 & - & 8 & 7 & 6 & 6 & 5 & - \\
\hline Ano $X n$ & 8 & 7 & 6 & 5 & 4 & - & 7 & 6 & 5 & 5 & 4 & - \\
\hline \multicolumn{13}{|c|}{ Número mínimo de irrigações realizadas em um ano para o cafeeiro (identificado em 10.000 anos simulados) } \\
\hline Implantação & 5 & 4 & 4 & 4 & 3 & - & 6 & 5 & 5 & 5 & 4 & - \\
\hline Ano 1-2 & 5 & 3 & 4 & 4 & 3 & - & 7 & 6 & 5 & 5 & 4 & - \\
\hline Ano 2-3 & 5 & 4 & 4 & 4 & 3 & - & 6 & 5 & 4 & 4 & 3 & - \\
\hline Ano $X n$ & 5 & 4 & 4 & 4 & 3 & - & 5 & 4 & 4 & 4 & 3 & - \\
\hline \multicolumn{13}{|c|}{ Número máximo de irrigações realizadas em um ano para o cafeeiro (identificado em 10.000 anos simulados) } \\
\hline Implantação & 12 & 11 & 10 & 9 & 7 & - & 13 & 12 & 9 & 9 & 7 & - \\
\hline Ano 1-2 & 12 & 10 & 10 & 8 & 6 & 一 & 11 & 10 & 7 & 7 & 6 & - \\
\hline Ano 2-3 & 11 & 11 & 9 & 7 & 5 & - & 10 & 8 & 7 & 7 & 6 & - \\
\hline Ano $X n$ & 11 & 10 & 9 & 6 & 5 & - & 9 & 8 & 6 & 6 & 5 & - \\
\hline
\end{tabular}




\section{CONCLUSÕES}

Os valores extremos e médios da ETc, I, $E R, D E F$ e o número de irrigações, simulados nas regiões de Lavras e Uberlândia para a cultura do cafeeiro, permitem concluir que: (a) A ETo média é predominantemente maior que a $P_{75 \%}$. O saldo positivo $\left(P_{75 \%}-E T_{0}\right)$ ocorre do final da primavera até o término do verão; (b) Em média, a ETc é igual a $839,8 \mathrm{~mm}$ ano $^{-1} \mathrm{em}$ Lavras e 937,7 mm ano ${ }^{-1} \mathrm{em}$ Uberlândia. Nos anos de implantação, 1-2 e 2-3, os valores da ETC são $35 \%$, 20\% e $10 \%$ menores que os valores verificados para a cultura adulta, respectivamente; (c) Desconsiderando o uso da irrigação e considerando a $P_{75 \%}$, apenas o ano de implantação não apresenta risco de ocorrer $D E F$ > $200 \mathrm{~mm} a^{-1}$. (d) Devido à deficiência e a fase fenológica do cafeeiro, especial atenção deve ser dada às irrigações realizadas de março a maio em Lavras, e de maio a junho e setembro a outubro em Uberlândia; (e) Em média, a cultura adulta do cafeeiro necessita entre 7 e 8 irrigações por ano, para aplicar um lâmina de irrigação entre $220,1 \mathrm{~mm}$ ano $^{-1}$ (manejo 5) a 382,4 $\mathrm{mm}^{2} \mathrm{ano}^{-1}$ (manejo 1).

\section{REFERÊNCIAS}

1. ABIC - ASSOCIAÇÃO BRASILEIRA DA INDÚSTRIA DE CAFÉ. Estatísticas da produção agrícola - café beneficiado. Disponível em: <http://www.abic.com.br/estat pagricola.html> Acesso em: 14 de agosto de 2006.

2. ANTUNES, F.Z. Aptidão climática de Minas Gerais para a cafeicultura. Informe Agropecuário, v. 4, n. 44, p. 6-8, 1978.

3. ANTUNES, F.Z. Caracterização climática do Estado de Minas Gerais. Informe Agropecuário, v. 12, n. 138, p. 9-13, 1986.

4. ASSAD, E.D; PINTO, H.S; ZULLO JUNIOR, J.; ÁVILA, A.M.H. Impacto das mudanças climáticas no zoneamento agroclimático do café no Brasil. Pesquisa Agropecuária Brasileira, v. 39, n. 11, p. 1057-1064, 2004.

5. ASSIS, F.N.; ARRUDA, H.V.; PEREIRA, A.R. Aplicações de estatística à climatologia: teoria e prática. Pelotas: Universitária/UFPel, 1996. $161 \mathrm{p}$.

6. CAMARGO, A.P. de.; PEREIRA, A.R. Prescrição de rega por modelo climatológico. Campinas: Fundação Cargil, 1990. $27 \mathrm{p}$

7. CAMARGO, A.P. de; CAMARGO, M.B.P. de. Definição e esquematização das fases fenológicas do cafeeiro arábica nas condições tropicais do Brasil. Bragantia, v. 60, n. 1, p. 65-68, 2001.

8. CASTRO NETO, P.; SILVEIRA, F.V. Precipitação provável para Lavras-MG, baseada na função de distribuição de probabilidade gama: período de 10 dias. Ciência e Prática, v. 7, n. 1, p. 58-65, 1983.

9. EVANGELISTA;A.W.P.; CARVALHO, L.G. de; SEDIYAMA, G.C. Zoneamento climático associado ao potencial produtivo da cultura do café no Estado de Minas Gerais. Revista Brasileira de Engenharia Agrícola e Ambiental, v. 6, n. 3, p. 445-452, 2002

10. FARIA, M.A; REZENDE, F.C. Cafeicultura empresarial: produtividade e qualidade - irrigação na cafeicultura. Lavras: UFLA/FAEPE, 1997.110 p. (Curso de Especialização "Lato Sensu" por Tutoria à Distância)

11. FRIZZONE, J.A.; ANDRADE JÚNIOR, A.S. de; SOUZA, J.L.M. de; ZOCOLER, J.L. Planejamento da irrigação: análise de decisão de investimento. Brasília: EMBRAPA, 2005. $627 \mathrm{p}$.

12. GOMES, S. Ajuste e avaliação de um modelo de balanço hídrico decendial e estudo dos limites de sua utilização em algumas localidades no Estado do Paraná. Curitiba, 2005. 103 f. Dissertação (Mestrado) - Universidade Federal do Paraná.

13. JORDÃO, C.; OLIVEIRA JR., O.R. de; MENDONÇA, R.L.P. de. Irrigação do cafeeiro - recomendações gerais. Monte Carmelo: Cooxupé, 1996. 32 p. (Boletim Técnico).

14. PEREIRA, A.R. Simplificando o balanço hídrico de Thornthwaite-Mather. Bragantia, v. 64, n. 2, p. 311-313, 2005.

15. PEREIRA, A.R.; VILLA NOVA, N.A.; SEDIYAMA, G.C. Evapo(transpi)ração. Piracicaba: FEALQ, 1997. 183 p.

16. PEZZOPANE, J.R.M.; PEDRO JR., M.J.; THOMAZIELLO, R.A.; CAMARGO, M.B.P. de. Escala para avaliação de estádios fenológicos do cafeeiro arábica. Bragantia, v. 62, n. 3, p. 499-505, 2003.

17. SANTINATO, R.; FERNANDES, A.L.T.; FERNANDES, D.R. Irrigação na cultura do café. Campinas: Arbore, 1996. $146 \mathrm{p}$.

18. SANTOS, C.M. dos; TEODORO, R.E.F.; MENDONÇA, F.C.; CAETANO, A.R.; DOMINGUES, E.P.; BRONZI, S.S. Diagnóstico da cafeicultura irrigada no cerrado. In: SIMPÓSIO BRASILEIRO DE PESQUISA EM CAFEICULTURA IRRIGADA, 1., 1998, Araguari. Anais. Uberlândia: UFU/ DEAGO, 1998. p.120-144.

19. SANTOS, E.R. dos; RIBEIRO, A.G. Clima e agricultura no município de Coromandel (MG). Caminhos de Geografia, v. 8, n. 13, p. 122-140, 2004

20. SOUZA, J.L.M.de. Modelo de análise de risco econômico aplicado ao planejamento de projetos de irrigação para cultura do cafeeiro. Piracicaba, 2001. 253 f. Tese (Doutorado) - Universidade de São Paulo, Escola Superior de Agricultura "Luiz de Queiroz".

21. SOUZA, J.L.M. de; FRIZZONE, J.A. Modelo aplicado ao planejamento da cafeicultura irrigada: I. Simulação do balanço hídrico e do custo com água. Acta Scientiarum, v. 25, n. 1, p. 103-112, 2003.

22. THORNTHWAITE, C.W.; MATTER, J.R. The water balance. Centerton: The Laboratory of Climatology, 1955, $104 \mathrm{p}$. (Publications in Climatology, v. 8, n. 1). 
